\section{In Vitro Antimicrobial Activity and Structure-activity Relationship of C-2 Triazolylthio and Pyridinylmethylthio Carbapenems}

\author{
C. Fiakpui, G. Thomas, M. P. Singh ${ }^{\dagger}$, \\ R. G. MICETICH and R. SINGH* \\ \#2, 4290-91A Street, Synphar Laboratories Inc., \\ Taiho Alberta Centre, Edmonton, \\ Alberta T6E 5V2, Canada
}

(Received for publication August 31, 1995)

The carbapenems are an important group of $\beta$-lactam antibiotics with unique nuclear structure that differs from the penam and cephem nuclei of penicillins and cephalosporins, respectively. Because of their unrivaled antibacterial spectrum and remarkable stability towards a wide range of $\beta$-lactamases as embodied in imipenem (1a) and the fact that even imipenem has certain drawbacks, it is not surprising that there has been a great deal of interest amongst medicinal chemists in finding new and improved carbapenems ${ }^{1 \sim 5)}$. Despite the inherent problem of chemical and metabolic instability combined with poor semi-synthetic methods for this class of compounds, considerable progress has been made. Two new carbapenems, meropenem (1b) and biapenem (1c) have been shown to possess better microbiological and pharmacokinetic profiles ${ }^{6,7)}$. Meropenem is a stable to renal DHP and it has recently been approved for clinical use in some countries. In recent years, a few other

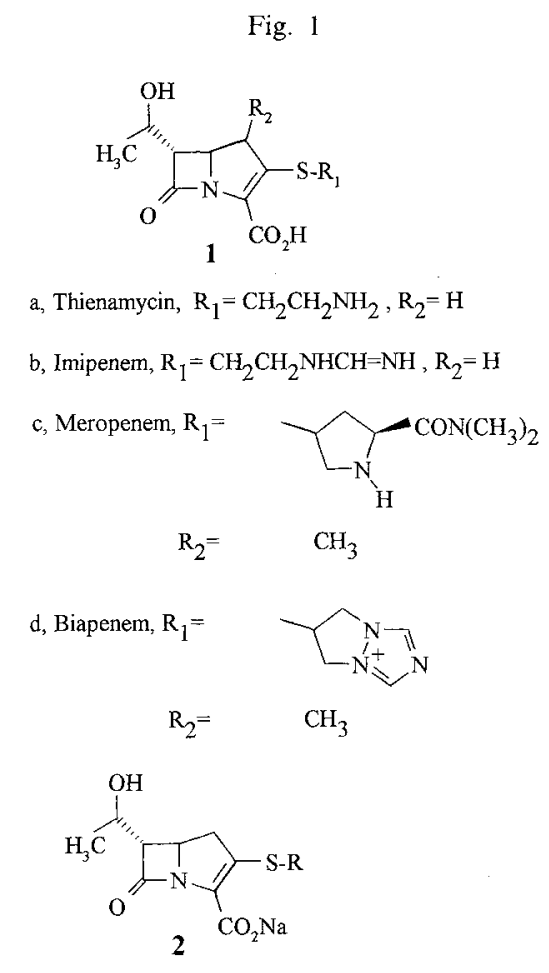

analogs such as DX-8739, GV-104326, BO-2727 and S-4661 have been reported to possess some advantages over the known derivatives ${ }^{8 \sim 11}$.

Although the low molecular weight, excellent $\beta$ lactamase stability and high affinity for bacterial PBPs of carbapenems provide exceptional antibacterial spectrum, the nature of $\mathrm{C}-2$ substitution has also been recognized as major contributor to carbapenems antibacterial properties. Presence of basic or quaternary amino moieties at $\mathrm{C}-2$ considerably improves the chemical stability and extends the antibacterial spectrum relative to compounds with less basic side chain at the same position ${ }^{5,12)}$.

In recent years, more attempts were made to improve the antimicrobial activity against clinically resistant gram negative strains including Pseudomonas spp. by changing the position 2 substituents with more basic or cationic substituents. There are a limited reports ${ }^{13)}$ on the effect of position 2 substituents in carbapenem class of compounds towards the gram positive strains including highly resistants $S$. aureus. In this paper we have focused our attention to study the effect of groups such as 3-substituted-1,2,4-triazol-5-yl-thio and halosubstituted pyridin-3-yl-methylthio at position 2 of carbapenems towards antimicrobial activity especially against Grampositive strains including highly resistant $S$. aureus.

\section{Chemistry}

The synthetic routes employed for the synthesis of title compounds are similar to those reported in the literature $^{14 \sim 16)}$ and the typical procedure is shown in scheme1. The bicyclic keto compound $\mathbf{3}$ was treated with diphenyl chlorophosphate in the presence of diisopropylamine to obtain a common intermediate enolphosphate 4 in situ which was then reacted with freshly prepared substituted 1,2,4-triazole-5-thione or halosubstituted pyridinyl-methylthiol afforded 2-substituted carbapenems 5. 5a: yield $51 \%$; IR (nujol) $\mathrm{cm}^{-1}: 1779,1718$, 1694; ${ }^{1} \mathrm{H}$ NMR $\left(200 \mathrm{MHz}, \mathrm{CDCl}_{3}\right) \delta: 1.28(3 \mathrm{H}, \mathrm{d}$, $J=6.2 \mathrm{~Hz}), 2.0(1 \mathrm{H}, \mathrm{brs}), 2.90(2 \mathrm{H}, \mathrm{m}), 3.2(1 \mathrm{H}, \mathrm{dd}$, $\left.J_{1}=6.7 \mathrm{~Hz}, J_{2}=2.8 \mathrm{~Hz}\right), 3.95(3 \mathrm{H}, \mathrm{s}), 4.14(2 \mathrm{H}, \mathrm{m}), 4.85$ $(2 \mathrm{H}, \mathrm{m}), 5.35(2 \mathrm{H}, \mathrm{m}), 6.0(1 \mathrm{H}, \mathrm{m}), 7.40(3 \mathrm{H}, \mathrm{m}), 8.15$ $(2 \mathrm{H}, \mathrm{m})$. Deprotection of allyl group with tetrakis triphenylphosphine palladium ( 0 ) in presence of triphenyl phosphine and sodium 2-ethyl hexanoate gave crude sodium salt of carbapenem derivative $\mathbf{2}$ which could be purified by either on a reverse phase (Whatman $\mathrm{MKC}_{18} \mathrm{~F}$ ) preparative plates using acetonitrile - water (94:6) mixture as developing solvent or column chromatography on dianion HP-20 afforded the foamy product after lyophilization. 2a: yield $21 \% ;{ }^{1} \mathrm{H}$ NMR $\left(200 \mathrm{MHz}, \mathrm{D}_{2} \mathrm{O}\right) \delta: 1.3(3 \mathrm{H}, \mathrm{d}, J=6 \mathrm{~Hz}), 2.52(1 \mathrm{H}, \mathrm{m})$, $2.85(1 \mathrm{H}, \mathrm{m}), 3.41\left(1 \mathrm{H}, \mathrm{dd}, J_{1}=5.6 \mathrm{~Hz}, J_{2}=2.7 \mathrm{~Hz}\right), 3.87$ $(3 \mathrm{H}, \mathrm{s}), 4.18(2 \mathrm{H}, \mathrm{m}), 7.54(3 \mathrm{H}, \mathrm{m}), 7.95(2 \mathrm{H}, \mathrm{m}) ; \mathrm{HPLC}$ purity $92 \%$. Similarily compounds $2 \mathbf{b} \sim 2 \mathbf{j}$ were synthesized, purified by chromatography and characterized by

$\dagger$ Present address: Wyeth-Ayerst Research, American Home Products Corporation, Pearl River, NY, U.S.A. 10965 
Scheme 1.

<smiles>COc1ccc(-c2nc(C)n(C)n2)cc1</smiles>

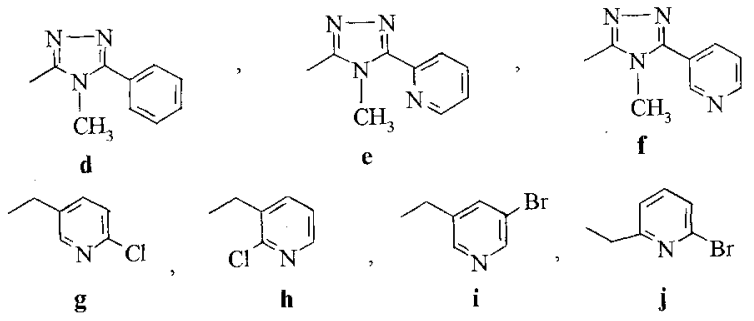

NMR and HPLC. The synthesis of substituted 1,2,4triazole-5-thione ${ }^{17)}$ and halosubstituted pyridinyl-methylthiol from halosubstituted pyridinyl-methanol ${ }^{18,19)}$ were done by following the synthetic procedure as described in literature.

\section{Results and Discussion}

Structure-activity relationship studies on a series of novel carbapenems $\mathbf{2}$ with triazolylthio and pyridinylmethylthio substituents at position 2 were studied. The in vitro antibacterial activities against a panel of Gram-positive and Gram-negative bacteria were determined by the agar dilution method as recommended in the National committee for Clinical Laboratory Standards ${ }^{20)}$. The MICs are reported in Table 1. Out of two classes triazolylthio carbapenem $(\mathbf{2 a} \sim \mathbf{2 f})$ and pyridinylmethylthio carbapenem $(\mathbf{2 g} \sim \mathbf{2 j})$ derivatives, the compounds $2 \mathbf{g} \sim 2 \mathbf{j}$ showed similar or slightly inferior activity than imipenem against most of the Gram-positive and Gram-negative bacteria with the exception of $P$ seudomonas aeruginosa isolates. The compounds $\mathbf{2 a}$ and 2b showed very poor activity against Gram-negatives but good activity against Gram-positives. Compound 2a exhibited $1 \sim 2$ fold better activity against MRSA (Sa 157-399 and Sa Amp81-30 than imipenem. Compounds $\mathbf{2 c} \sim 2$ f exhibited several fold inferior activity against

Table 1. Antibacterial activity of $\mathrm{C}-2$ triazolylthio and pyridylthiomethyl carbapenems 5 .

\begin{tabular}{|c|c|c|c|c|c|c|c|c|c|c|c|}
\hline Test organisms & Imipenem & $2 \mathbf{a}$ & $2 \mathrm{~b}$ & $2 \mathrm{c}$ & $2 d$ & $2 \mathrm{e}$ & $2 f$ & $2 g$ & $2 \mathrm{~h}$ & $2 \mathbf{i}$ & $2 \mathbf{j}$ \\
\hline E.c. ATCC 25922 & 0.06 & 128 & $>128$ & 32 & 16 & 8.0 & 1.0 & 0.5 & 8.0 & 4.0 & 2.0 \\
\hline E.c. DCO & 0.25 & 128 & $>128$ & 32 & 8 & 4.0 & 1.0 & 0.5 & 8.0 & 4.0 & 1.0 \\
\hline E.c. DC2 & 0.25 & 0.25 & 0.50 & 1.0 & 0.25 & 0.5 & 0.5 & $<0.06$ & 0.5 & 0.12 & 0.12 \\
\hline E.c. SHV 1 & 0.06 & 128 & $>128$ & 16 & 8 & 4.0 & 1.0 & 0.25 & 4.0 & 2.0 & 1.0 \\
\hline E.c. TEMI & 0.06 & 128 & $>128$ & 16 & 8 & 4.0 & 2.0 & 0.25 & 4.0 & 2.0 & 1.0 \\
\hline E.c. TEM2 & 0.06 & 32 & 128 & 8.0 & 4.0 & 2.0 & 2.0 & $<0.06$ & 2.0 & 0.5 & 0.25 \\
\hline E.c. OXAl & 0.12 & $>128$ & $>128$ & 32 & 16 & 4.0 & 2.0 & 0.5 & 8.0 & 4.0 & 2.0 \\
\hline E.c. OXA3 & 0.12 & 128 & $>128$ & 16 & 8.0 & 4.0 & 1.0 & 0.5 & 8.0 & 2.0 & 1.0 \\
\hline E.cl. ATCC 23355 & 0.25 & $>128$ & $>128$ & 32 & 32 & 16 & 8.0 & 2.0 & 32 & 16 & 4.0 \\
\hline E.cl. (Multi Resist) & 1.0 & $>128$ & $>128$ & $>128$ & 128 & 64 & 64 & 32 & $>128$ & 64 & 32 \\
\hline K.p. АТСС 13833 & 0.5 & $>128$ & $>128$ & 32 & 8.0 & 4.0 & 1.0 & 1.0 & 16 & 8.0 & 4.0 \\
\hline K.ox. ATCC 15764 & 0.12 & 128 & 128 & 8.0 & 1.0 & 0.5 & 0.5 & 0.12 & 2.0 & 1.0 & 0.25 \\
\hline Sh.so. ATCC 11060 & 0.12 & 128 & $>128$ & 32 & 8.0 & 2.0 & 1.0 & 1.0 & 4.0 & 1.0 & 1.0 \\
\hline C.f. (R-ceph) & 0.25 & $>128$ & $>128$ & 128 & 32 & 8.0 & 16 & 2.0 & 16 & 8.0 & 2.0 \\
\hline P.a. ATCC 27853 & 2.0 & $>128$ & $>128$ & $>128$ & $>128$ & $>128$ & $>128$ & $>128$ & $>128$ & $>128$ & $>128$ \\
\hline P.a. PSE1 & 1.0 & $>128$ & $>128$ & $>128$ & $>128$ & $>128$ & $>128$ & $>128$ & $>128$ & $>128$ & $>128$ \\
\hline P.a. PSE2 & 1.0 & $>128$ & $>128$ & $>128$ & $>128$ & $>128$ & $>128$ & $>128$ & 8.0 & 2.0 & 1.0 \\
\hline P.a. PSE3 & 1.0 & $>128$ & $>128$ & $>128$ & $>128$ & $>128$ & $>128$ & $>128$ & $>128$ & $>128$ & $>128$ \\
\hline P.a. PSE4 & 1.0 & $>128$ & $>128$ & $>128$ & $>128$ & $>128$ & $>128$ & $>128$ & $>128$ & $>128$ & $>128$ \\
\hline P.ret. ATCC 29944 & 0.5 & 128 & $>128$ & 16 & 4.0 & 1.0 & 2.0 & 0.50 & 4.0 & 1.0 & 0.25 \\
\hline P.m. ATCC 2675 & 0.5 & $>128$ & $>128$ & 8.0 & 4.0 & 1.0 & 2.0 & 1.0 & 2.0 & 0.5 & 0.25 \\
\hline S.mar. ATCC 2982 & 1.0 & $>128$ & $>128$ & $>128$ & $>128$ & $>128$ & $>128$ & 4.0 & 32 & 16 & 8.0 \\
\hline S.a. ATCC 29213 & $<0.015$ & 0.12 & 0.12 & 0.5 & 0.12 & 0.25 & 0.25 & $<0.06$ & 0.25 & 0.06 & 0.12 \\
\hline S.a. JHHD078 & $<0.015$ & 0.06 & 0.12 & 0.5 & 0.12 & 0.25 & 0.25 & $<0.06$ & 0.25 & 0.06 & 0.12 \\
\hline S.a. JHHM 241 & 0.06 & 0.12 & 0.25 & 2.0 & 0.25 & 0.5 & 0.5 & 0.12 & 0.5 & 0.06 & 0.25 \\
\hline S.a. $157-399$ & 8.0 & 2.0 & 2.0 & 32 & 8.0 & 64 & 64 & 8.0 & 64 & 8.0 & 32 \\
\hline S.a. AMP81-3 & 2.0 & 1.0 & 4.0 & 8.0 & 2.0 & 8.0 & 8.0 & 8.0 & 16 & 2.0 & 1.0 \\
\hline
\end{tabular}

Agar dilution method; medium, Mueller Hinton agar; inoculum, $10^{4} \mathrm{cfu} / \mathrm{spot}$; incubation, 18 hours at $35^{\circ} \mathrm{C}$. E.c.: Escherichia coli, E.cl.: Enterobacter cloacae, K.p.: Klebsiella pneumoniae, K. ox.: Klebsiella oxytoco, Sh.so.: Shigella sonnei, C.f.: Citrobacter freundii, P.a.: Pseudomonas aeruginosa, P.ret.: Providencia rettgeri, P.m.: Proteus mirabilis, S.ma.: Serratia marcescens, S.a.: Staphylococcus aureus. 
Table 2. Permeability profile of C-2 triazolyl thio and pyridyl thiomethyl carbapenems 5 .

\begin{tabular}{ccccc}
\hline \multirow{2}{*}{$\begin{array}{c}\text { Compound } \\
\text { No. }\end{array}$} & DCO/DC2 & $\begin{array}{c}\text { E. coli } \\
\text { DCO }\end{array}$ & $\begin{array}{c}\text { E. coli } \\
\text { DC2 }\end{array}$ & $\begin{array}{c}\text { E. coli } \\
\text { ATCC } 25922\end{array}$ \\
\cline { 2 - 5 } & 512 & 128 & 0.25 & 128 \\
\hline $\mathbf{2 a}$ & 512 & $>128$ & 0.5 & $>128$ \\
$\mathbf{2 b}$ & 32 & 32 & 1.0 & 32 \\
$\mathbf{2 c}$ & 32 & 8.0 & 0.25 & 16 \\
$\mathbf{2 d}$ & 8.0 & 4.0 & 0.5 & 8.0 \\
$\mathbf{2}$ & 2.0 & 1.0 & 0.5 & 1.0 \\
$\mathbf{2}$ & 8.0 & 0.5 & $<0.06$ & 0.50 \\
$\mathbf{2}$ & 16 & 8.0 & 0.5 & 8.0 \\
$\mathbf{2}$ & 32 & 4.0 & 0.12 & 4.0 \\
$\mathbf{2}$ & 8.0 & 1.0 & 0.12 & 2.0 \\
$\mathbf{2}$ & 1.0 & 0.25 & 0.25 & 0.06 \\
\hline Imipenem & & & &
\end{tabular}

Gram-negative but moderate activity against Grampositive bacteria as compared to imipenem. In carbapenem derivatives $(\mathbf{2} \mathbf{g} \sim \mathbf{2} \mathbf{j})$, the halogen substitution at pyridine and linkage between pyridine and methylthio had moderate effect on the antimicrobial activity. Compound $2 \mathrm{~g}$ having 6-chloro-pyridin-3-yl-methylthio substituent at position 2 showed similar antimicrobial activity whereas the other compounds are less active than the imipenem.

Keeping the favorable MRSA activity of $\mathbf{2 a}$ in mind several other analogs were prepared and evaluated. None of these compounds showed improved activity over compound 2a. It appears that the position of methyl and the nature of the aryl group on the triazole has a predominant effect on the activity against Gram-negative strains but has only a minor effect on the activity against the Gram-positives. The methyl substitution at N-4 and pyridin-3-yl at C-3 of triazole in the compounds were favorable for activity against both Gram-positive and Gram-negative bacteria.

The nature of the substitutent at $\mathrm{C}-2$ position has considerable effect on the permeability of compounds through the outer membrane of Gram-negative bacteria $^{5,12)}$. We tested our compounds against two strains of $E$. coli, E. coli DCO (with normal permeability barrier) and $E$. coli DC2 (permeability mutant of $E$. coli DCO having no permeability barrier). The MICs of C-2 triazolyl thio and pyridinyl thiomethyl carbapenems 2 against these strains and their ratio (MIC DC0/MIC DC2) are given in Table 2. The ratio of MICs of these two strains are indicative of permeability profile of each derivatives. When a compound is equally active against both strains the MIC DC0/MIC DC2 ratio approaches to 1 , as seen in the case of imipenem. Low values indicate that the compound has no problem of crossing the outer membrane. Higher values suggest permeability problem as seen in the case of $\mathbf{2} \mathbf{a} \sim \mathbf{2} \mathbf{d}$ and $\mathbf{2 h} \sim \mathbf{2} \mathbf{i}$ (Table 2).

\section{Acknowledgments}

The authors wish to thanks Mr. B. LIX for NMR spectral analysis and Ms. JoYCE NG for purity analysis of sodium salt of final compounds by HPLC.

\section{References}

1) Albers-Schonberg, G.; B. H. Arison, O. D. Hensens, J. Hirshfield, K. Hoogstein, E. A. KaczKa, R. E. Rhodes, J. S. Khan, F. M. Kahan, R. W. Ratcliffe, E. Walton, L. J. Ruswinkle, R. B. Morin \& B. G. Christensen: Structure and absolute configuration of thienamycin. $\mathbf{J}$. Am. Chem. Soc. 100: 6491 6499, 1978

2) Leanza, W. J.; K. J. Wildonger, T. W. Miller \& B. G. CHRISTENSEN: $\mathrm{N}$-acetimidoyl- and $\mathrm{N}$-formimidoylthienamycin derivatives: antipseudomonal $\beta$-lactam antibiotics. J. Med. Chem. 22: 1435 1436, 1979

3) Ratcliffe, R. W. \& G. Albers-Schonberg: The Chemistry of Thienamycin and other Carbapenem Antibiotics in Chemistry and Biology of $\beta$-lactam Antibiotics. Eds., Morin, R. B. and M. Gorman, $227 \sim 313$, Academic Press, New York, 2, 1982

4) WISE, R.: In vitro and pharmacokinetic properties of the carbapenems. Antimicrobial Agents Chemother. 30: $343 \sim 349,1986$

5) Livingstone, D.; M. J. Gill \& R. Wise: Mechanism of resistance to the carbapenems. J. Antimicrob. Chemother. 35: $1 \sim 5,1995$

6) Hanabe, E.; Y. Kawai, K. Kanazawa, M. Otsuki \& T. NISHIO: In vitro and in vivo antibacterial activities of meropenem, a new carbapenem antibiotic. Drugs Exptl. Clin. Res. 18: $37 \sim 46,1992$

7) Catchpole, C. R.; R. Wise, D. Thornber \& J. M. ANDREWS: In vitro activity of L-627, a new carbapenem. Antimicrob. Agents Chemother. 36: $1928 \sim 1934,1992$

8) Nishi, T.; M. Takemura, T. Saito, Y. Ishida, K. Sugita, M. Houmura, H. Ishil, K. Sata, I. Hayakawa \& T. HAYANO: DX-8739, a new antipseudomonal carbapenem antibiotic: structure-activity relationship and in vitro activity. Program and Abstracts of the 32nd Intersci. Conf. on Antimicrobial Agents Chemother., p. 132, No. 131, Anaheim, California, Oct. $11 \sim 14,1992$

9) Perboni, A.; D. Donati, T. Rossi, B. Tamburini, G. TARZIA \& G. GAVIRAGHI: Tricyclic $\beta$-lactams(tribactam): potent DHP-1 and $\beta$-lactamase stable antibiotics. Program and Abstracts of the 32nd Intersci. Conf. on 
Antimicrobial Agents Chemother., p. 132, No. 127, Anaheim, California, Oct. $11 \sim 14,1992$

10) Asahi, Y.; S. MiYazaKi \& K. Yamaguchi: In vivo and in vitro antibacterial activities of $\mathrm{BO}-2727$, a new carbapenem. Antimicrobial Agents Chemother. 39: $1030 \sim 1037,1995$

11) Sasaki, S.; K. Murakami, Y. Nishitan \& S. Kuwahara: S-4661, a new carbapenem: in vitro antibacterial activity. Abstracts of the 34th Intersci. Conf. on Antimicrobial Agents Chemother., p. 32, No. F-33, Oct. 4 7, Orlando, 1994

12) Sumta, Y.; H. Yamaga \& M. Sunagawa: The effect of $1 \beta$-methyl substituent and the basicity in $\mathrm{C}-2$ side chain in carbapenem antibiotic on the activity against Pseudomonas aeruginosa oprD2 and nal $\mathrm{B}$ mutants. J. Antibiotics 48: 89 91, 1995

13) Sendo, Y.; M. KiI, M. Sakanoue, K. Motokawa \& Y. KIMURA: Synthesis and antibacterial activity of 1substituted methyl carbapenems. Chem. Pharm. Bull. 40: $2410 \sim 2418,1992$

14) KIM, C. U.; B. Y. LuH, P. F. Misco \& M. J. M. HiтCHCOCK: Synthesis and in vitro activity of $1 \beta$-methyl C-2 quaternary heterocyclic alkylthio carbapenems. J.
Med. Chem. 32: 601 604, 1989

15) Shih, D. H.; F. Baker, L. Cama \& B. G. Christensen: Synthetic carbapenem antibiotics I. 1 $\beta$-Methylcarbapenem. Heterocycles 21: $29 \sim 40,1984$

16) Kim, C. U.; P. F. Misco, B. Y. LuH \& M. J. M. HıтсHCOCK: Synthesis and in vitro Activity of C-2 quaternary heterocyclic alkylthio carbapenems. J. Antibiotics 60: $1707 \sim 1715,1987$

17) Kane, J. W.; M. W. Dudley, S. M. Soresen \& F. P. MILLER: 2,4-Dihydro-3 $H$-1,2,4-triazole-3-thiones as potential antidepressant agents. J. Med. Chem. 31: $1253 \sim 1258,1988$

18) Jones, R. G. \& E. C. Kornfeld: Lithium aluminum hydride reduction of pyridine carboxylic esters: Synthesis of vitamin $\mathbf{B}_{6}$. J. Am. Chem. Soc. 73: 107, 1951

19) Barnes, J. H.; F. R. Hartley \& C. E. I. Jones: The preparation of 4- and 6-chloro-2-chloromethylpyridine. Tetrahedron 38: 3277 3280, 1982

20) National Committee for Clinical Laboratory Standards 1991. Methods for dilution antimicrobial susceptibility tests for bacteria that grow aerobically: approved standard M7-A. National Committee for Clinical Laboratory Standards, Villannova, $\mathrm{Pa}$ 